\title{
Oral vibrotactile stimulation: A study of practice effect*
}

\author{
DONALD J. FUCCI, PATRICK McCAFFREY, ANN P. CURTIS, and ROBERT BLACKMON \\ School of Hearing and Speech Sciences, Ohio University, Athens, Ohio 45701
}

\begin{abstract}
This study was designed to examine the effect of practice on lingual vibrotactile thresholds. Twenty Ss between the ages of 19 and 28 years were used in the experiment. Ten of the Ss were each given a 5 -min orientation period before threshold readings were taken. The remainder also went rhrough a 5-min orientation period, but in addition received $30 \mathrm{~min}$ of practice. The practice group produced statistically significant lower and less variable thresholds than the nonpractice group at two of the three frequencies tested. These data indicate that familiarity with the instrumentation and required task is increased with prolonged practice, resulting in more precise threshold measurements.
\end{abstract}

It has been suggested that certain sensory modalities are important to the monitoring of speech production. Previous research has established the importance of the feedback mechanism in speech production (Fairbanks, 1954; Van Riper \& Irwin, 1962; Mysak, 1966).

Various methods have been used to examine the structures involved in the speech process. The ability to recognize the shape of objects through feedback produced by the sense of touch within the mouth has been indicative of normal neural functioning (Forster, 1962). Other methods have also been used to assess oral peripheral and central tactile processes. These have included the use of electrical stimulation, two-point discrimination, and texture discrimination (Grossman, Hattis, \& Ringel, 1965; Ringel \& Ewanowski, 1965).

In addition to the procedures mentioned above, vibration has been used to assess peripheral tactile sensory function (Geldard, 1940). It has all the advantages of the other methods and permits the modification of the parameters of frequency, amplitude, and time. Furthermore, it employs the use of various psychophysical methods in determining thresholds of vibration for different bodily structures.

A number of investigators have attempted to define the most appropriate methods for establishing vibrotactile thresholds. Gilmer (1935) and Verrillo (1963) have studied the effects of contactor size on threshold measurements. Hall, Fucci, and Arnst (1972) have examined the psychophysical methods of limits and adjustment, and Fucci, Arnst, Telage, and McCaffrey (1973) have compared ascending and descending thresholds using pulsed and continuous stimulation.

One procedural aspect that has not been studied is the effect of practice on threshold results. A review of the literature has yielded varied information regarding $S$ orientation. Verrillo (1966) and Fucci (1972) used preexperiment instruction only, while Hall, Fucci, and Arnst (1972) provided a 1-h training period prior to the

*Sponsored by James L. Bruning, who takes full editorial responsibility for its contents. experiment. The present investigation was designed to study practice effect on oral vibrotactile thresholds.

\section{METHOD}

\section{Subjects}

Twenty Ss were selected from the Ohio University School of Hearing and Speech Sciences. They ranged in age from 19 years, 2 months to 28 years, 8 months and reported no history of speech sensory and/or motor impairments. The Ss were divided into two groups of 10 each. Group 1 was designated the experimental group and Group 2 the control group.

\section{Apparatus}

The equipment used in this study has been described by Fucci and Kelly (1972). The stimulus unit consisted of an audio generator, an electrical switch-interval timer, an amplifier, a vibrator, a probe, and a contactor. The pulsed signal generator had a $50 \%$ duty cycle (on $1 / 2 \mathrm{sec}$ and off $1 / 2 \mathrm{sec}$ ) with a rise and decay time of $100 \mathrm{msec}$. The measurement unit included an accelerometer, a microphone power supply, and a vacuum tube voltmeter. A white noise generator was used to provide auditory masking.

\section{Procedure}

Each $\mathrm{S}$ was seated in a dental chair with his tongue extended between two sterilized plastic disks. The tongue was clamped in position tightly enough to hold it without effecting normal circulation. The stimulus was applied to the anterior midline region of the tongue through a free surround disk containing a hole having a diameter $2 \mathrm{~mm}$ greater than that of the contactor. The probe and contactor were lowered until an ohmmeter recorded contact with the lingual surface. After contact was established, the probe was lowered $1 \mathrm{~mm}$ further into the tongue. Lingual vibrotactile thresholds were obtained at 100 , 300 , and $500 \mathrm{~Hz}$ for all Ss. These frequencies were selected because they represent the range of frequencies to which the tongue is most sensitive (Fucci et al, 1971).

Each $\mathrm{S}$ was required to respond by raising his hand as soon as he detected the pulsed vibratory stimulus. The median of three millivolt readings was accepted as the lingual threshold and later changed to displacement in microns with the standard $\mathrm{g}$ formula for acceleration conversion.

Those Ss making up the control group were each given a 5-min orientation period before threshold readings were recorded. The Ss in the experimental group also underwent a 5-min orientation but in addition received $1 / 2 \mathrm{~h}$ of practice. During this session, each $S$ was permitted three trial runs at 100,300 , and $500 \mathrm{~Hz}$, and allowed to rest for $5 \mathrm{~min}$ between frequencies. Threshold readings were recorded at the completion of the practice period. 
Table 1

Means and Standard Deviations Obtained for Each Group of Threshold Data

\begin{tabular}{lccc}
\multicolumn{2}{c}{ Threshold } & \multicolumn{1}{c}{$\begin{array}{c}\text { Mean } \\
\text { (in microns) }\end{array}$} & SD \\
\hline Control Ss & $100 \mathrm{~Hz}$ & 2.16 & 1.02 \\
Control Ss & $300 \mathrm{~Hz}$ & 1.45 & 1.00 \\
Control Ss & $500 \mathrm{~Hz}$ & 1.70 & 0.88 \\
Experimental Ss & $100 \mathrm{~Hz}$ & 1.16 & 0.40 \\
Experimental Ss & $300 \mathrm{~Hz}$ & 0.87 & 0.33 \\
Experimental Ss & $500 \mathrm{~Hz}$ & 0.82 & 0.34 \\
\hline
\end{tabular}

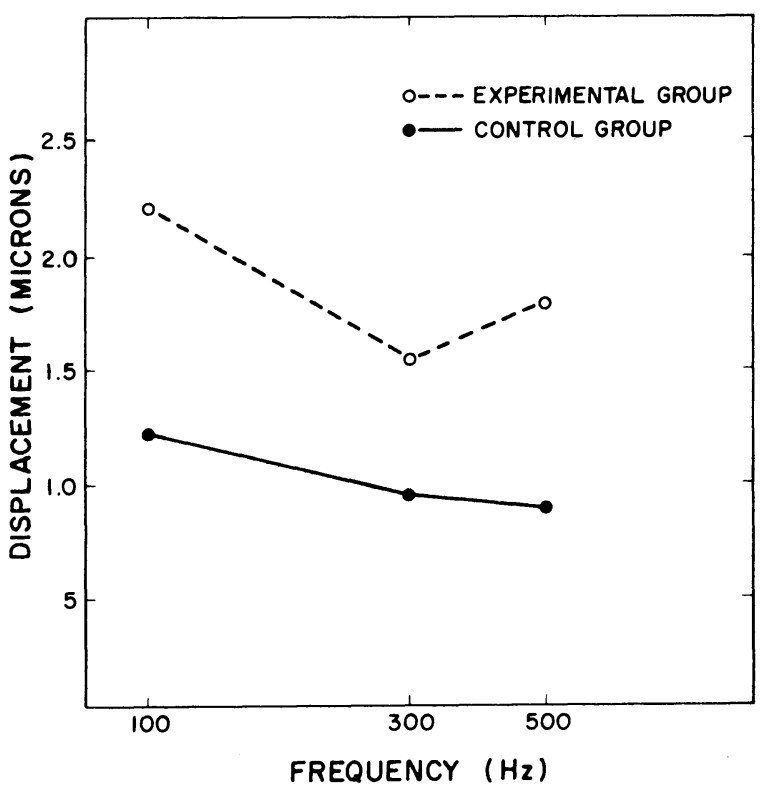

Fig. 1. A graphic representation of the mean vibrotactile thresholds (in microns) for the control and experimental Ss plotted as a function of frequency.

Table 2

Summary of $t$ Test Comparisons of Threshold Data

\begin{tabular}{lll}
\hline \multicolumn{1}{c}{ Comparison } & & \multicolumn{1}{c}{ t Test } \\
\hline & $100 \mathrm{~Hz}$ & $2.905^{*}$ \\
Control vs Experimental & $300 \mathrm{~Hz}$ & 1.745 \\
& $500 \mathrm{~Hz}$ & $2.925^{*}$ \\
\hline
\end{tabular}

${ }^{*} p<.01$

\section{RESULTS}

Data in microns were averaged for Ss in the following conditions: control Ss $(100,300$, and $500 \mathrm{~Hz})$; experimental Ss $(100,300$, and $500 \mathrm{~Hz})$. These results appear in Table 1. Figure 1 is a graphic representation of the mean vibrotactile thresholds (in microns) for the control and experimental Ss plotted as a function of frequency.

To determine what appears to be a definite difference between control and experimental Ss' thresholds at each frequency, the individual S's thresholds (microns) for each frequency were submitted to a $t$ test for analysis.
The $t$ values obtained for the control and experimental Ss at 100,300 , and $500 \mathrm{~Hz}$ were $2.905,1.745$, and 2.925 , respectively. The critical value for a .01 level test is $t_{.99}=2.878(\mathrm{df}=18)$. These results indicate that there is a statistically significant difference in thresholds for the control and experimental Ss for the frequencies of 100 and $500 \mathrm{~Hz}$. There is not a statistically significant difference $(p>.01)$ between the threshold groups at $300 \mathrm{~Hz}$; however, examination of Fig. 1 does reveal a discernible difference between groups at this frequency as well. A summary of the $t$ test comparisons appears in Table 2.

The threshold standard deviations for both groups are shown in Table 1. It can be seen that the standard deviations for the control Ss are indicative of a greater amount of dispersion of threshold scores for each frequency than those for the experimental Ss.

\section{DISCUSSION}

Learning has been defined as the relatively permanent change in behavior occurring as the result of practice. A definition such as this excludes behavioral changes resulting from transient or temporary behavior (fatigue, drugs, adaptation), maturation of the organism, disease or physical abnormalities (Hilgard \& Atkinson, 1967).

The present investigation, a preliminary study in the area of qualitative changes with practice, incorporated a massed practice technique. It appears from the results that prolonged practice enables Ss to lower their threshold scores. It also enables them as a group to produce more consistent thresholds. It can be surmised that vibrotactile thresholds obtained from the tongue are affected by the amount of practice provided. It should be noted that these results do not imply increased oral sensitivity with practice. The data, instead, suggest changes resulting from familiarity with the task and instrumentation used.

Learning curves have been used to graphically represent responses which indicate qualitative changes in efficiency. Learning theorists have developed these curves through the use of massed practice (Hilgard \& Atkinson, 1967). Future vibrotactile studies in the area of practice effect should consider using learning curves. This would provide a way of determining the optimal practice period; the amount of practice which produces the lowest possible and least variable thresholds.

\section{REFERENCES}

Fairbanks, G. Systematic research in experimental phonetics. Journal of Speech \& Hearing Disorders, 1954, 19, 133-140.

Forster, F. Sy nopsis of neurology. St. Louis: Mosby, 1962.

Fucci, D. J. Oral vibrotactile sensation: An evaluation of normal and defective speakers. Journal of Speech \& Hearing Research, $1972,15,179-184$.

Fucci, D. J., Arnst, D. J., Telage, K. M., \& McCaffrey, P. K. Measurement of lingual vibrotactile sensitivity using pulsed and continuous stimulation. Bulletin of the Psychonomic Society, 1973, 2, 85-86.

Fucci, D. J., Hall, D. E., \& Weiner, F. F. Normative study of oral and non-oral structures using vibrotactile stimuli. Perceptual \& Motor Skills, 1971, 33, 1099-1105.

Fucci, D. J., \& Kelly, D. H. New instrumentation for research on vibrotactile sensitivity of the tongue. The Review of Scientific Instruments, 1972, 43, 1748-1751.

Geldard, F. A. The perception of mechanical vibration: III. The frequency function. Journal of General Psychology, 1940, 22, 281-289.

Gilmer, B. von $H$. The measurement of the sensitivity of the skin to mechanical vibration. Journal of General Psychology, 1935, 13, 42-61.

Grossman, R., Hattis, B., \& Ringel, R. Methods of determining oral-tactile experience. Archives of Oral Biology, 1965, 10, 691-705. 
Hall, D. H., Fucci, D. J., \& Arnst, D. J. Vibrotactile stimulation: An investigation of psychophysical methods for establishing threshold. Perceptual \& Motor Skills, 1972, 34, 891-898.

Hilgard, E. R., \& Atkinson, R. C. Introduction to psychology. New York: Harcourt, Brace, \& World, 1967.

Mysak, E. D. Speech pathology and feedback theory. Spring field, Illinois: Thomas, 1966.

Ringel, R., \& Ewanowski, S. Oral perception: 1. Two-point discrimination. Journal of Speech \& Hearing Research, 1965, 8, 389-398.

Van Riper, C., \& Irwin, J. Voice and articulation. Englewood
Cliffs, New Jersey: Prentice-Hall, 1962.

Verrillo, R. T. Effect of contactor area on the vibrotactile threshold. Journal of the Acoustical Society of America, $1963,35,1962-1966$.

Verrillo, R. T. Vibrotactile sensitivity and the frequency response of the Pacinian corpuscle. Psychonomic Science, $1966,4,135-146$.

(Received for publication December 28, 1973.)

\section{Forgetting of visually presented words after retention intervals filled with detection of acoustic signals*}

\author{
BARRY LESHOWITZ and PATRICK M. ZUREK $\dagger$ \\ Arizona State University, Tempe, Ariz. 85281
}

and

\author{
DONALD ROBBINS \\ Emory University, Atlanta, Ga. 30322
}

Recall of common one-syllable words following an interpolated interval of either 15 or $30 \mathrm{sec}$ was investigated. Two filler tasks were used: a simple detection task (tone in noise) or discrimination of tonal amplitude. Of the $20 \mathrm{Ss}, 10$ showed appreciable forgetting. These data question the conclusion that memory loss due to the passage of time does not occur in short-term memory.

Recently, Reitman (1971) developed a procedure to study the possible loss of information from short-term memory when the effects of interference and rehearsal are minimized or eliminated. Specifically, she asked: Does information in short-term memory decay as a result of the passage of time? In order to eliminate rehearsal, Reitman used a modification of the Peterson \& Peterson (1959) paradigm. Stimulus material (to-be-recalled) was presented to S, followed by a $15-\mathrm{sec}$ filler task designed to prevent rehearsal and to interfere minimally with the to-be-remembered material. She used three different filler tasks. One was the detection of a pure tone in a continuous background of white noise, while the other two tasks were the detection of the spoken syllable "toh" in a background of "dohes"; one condition required $\mathrm{S}$ to press a key as soon as a "toh"

\footnotetext{
*This research was supported by United States Public Health Service Grant MH 20301 and by a contract from the Human Resources Laboratory, Flying Training Division at Williams Air Force Base in Arizona.

tRequests for reprints should be sent to: Barry Leshowitz, Department of Psychology, Arizona State Univeristy, Tempe, Ariz. 85281 .
}

was heard, while for the second condition $\mathrm{S}$ had to also say "toh" aloud.

Reitman (1971) found very little forgetting after $15 \mathrm{sec}$ for the tone-detection filler task, but found some for the syllable filler tasks. Mean retention in tone detection was $92 \%$, and for the syllabic identification task it was about $75 \%$. In the tonal-detection experiment, when no signal was presented in the retention interval and no false alarms were recorded, 13 Ss actually showed $100 \%$ recall while the remaining 5 showed between $67 \%$ and $89 \%$ recall. Atkinson \& Shiffrin (1971) reported replicating Reitman's results using the tone-detection filler task for intervals of 1,8 , and $40 \mathrm{sec}$.

Reitman (1971) and Atkinson \& Shiffrin (1971) concluded, based on these data, that there is no support for the proposition of temporal loss in short-term memory. Because this conclusion has important implications for theories of the memorial process, we must not minimize the importance of a basic assumption that is being made with regard to the control of rehearsal. Both Reitman (1971) and Atkinson \& Shiffrin (1971) told Ss not to rehearse during the detection interval. In fact, Reitman's (1971) data are based on 18 Ss who said, on a posttask questionnaire, that they did not rehearse. She eliminated the data of 13 Ss who said that, contrary to instructions, they had indeed rehearsed. As mentioned earlier, although 13 of Reitman's Ss in the tone detection filler task recalled $100 \%$ of the words when the retention interval was empty, 5 of them did show forgetting. This represents a considerable amount of variability between Ss and may reflect the distribution of the ability of a $S$ to rehearse the verbal material and simultaneously do the signal-detection task. It does not seem unreasonable to argue that nonverbal acoustic information may be processed independently of verbal material presented visually. Thus, rehearsal of the verbal material would 